\title{
A New Approach for the Study of Gas-Phase Ion-Ion Reactions Using Electrospray Ionization
}

\author{
Rachel R. Ogorzalek Loo, Harold R. Udseth, and Richard D. Smith \\ Chemical Methods and Separations Group, Chemical Sciences Department, Pacific Northwest Laboratory, \\ Richland, Washington, USA
}

\begin{abstract}
A simple flow reactor which facilitates the study and application of ion-ion and ion-molecule reactions at near atmospheric pressures is reported. Reactant ions were generated by electrospray ionization and discharge ionization methods, although any ionization sources amenable to atmospheric pressure may be used. Ions of opposite charge are generated in spatially separate ion sources and are swept into capillary inlets where the flows are merged and where reaction(s) can occur. Among the reactions investigated were the partial neutralization of multiply protonated polypeptides and proteins such as melittin, bradykinin, cytochrome $c$, and myoglobin by reaction with discharge-generated anions, the partial neutralization of multiply charged anions of oligodeoxyadenylic acid $\left(\mathrm{d}(\mathrm{pA})_{3}\right)$ by reaction with discharge-generated cations, the partial neutralization of bovine A-chain insulin anions by reaction with myoglobin $[\mathrm{M}+\mathrm{nH}]^{\mathrm{n}+}$ ions, and the reaction of multiply protonated melittin with discharge-generated cations. The cation-anion reactions generally resulted in a shift to lower charge (higher mass-to-charge ratio) in the products' charge stale distributions and the transfer of solvent molecules to the macromolecule products. Multiply protonated melittin was detected in a less highly solvated state with the positive discharge in operation. (J Am Soc Mass Spectrom 1992, 3, 695-705)
\end{abstract}

$\mathrm{D}$ espite the importance of ion-ion neutralization and recombination reactions in chemistry, gasphase ion-ion studies have received only a small fraction of the attention granted to ion-neutral reactions. Previous theoretical and experimental studies [1-3] have examined reactions of small ionic species relevant to plasma, flame, and atmospheric chemistry, but there have been no literature reports concerning ion-ion interactions of large gas-phase molecules, despite their possible relevance to important solutionphase processes. No doubt this absence can be attributed to the dearth of methods capable of generating such ions. Recently developed electrospray ionization (ESI) techniques efficiently produce such anionic and cationic species at atmospheric pressure [4-10]. In this article we provide a detailed report on methods developed for gas-phase ion-ion reaction studies along with several examples of reactions of highly charged macroions generated by ESI.

Electrospray ionization transfers nonvolatile species from solutions into the gas phase, generating multiply charged ions from many classes of high molecular weight compounds [4-16]. Multiple charging is beneficial to our mass spectrometric studies because residual charges still allow sensitive detection even after

Address reprint requests to Richard D. Smith, Chemical Methods and Separations Group, Chemical Sciences Department, Pacific Northwest Laboratory, Richland, WA 99352. one or more charge sites have been neutralized, Our initial investigations have concentrated on processes such as "partial" neutralization (where multiply charged cations react with singly or multiply charged anions to produce less highly charged species), and on possible reactions between ions of the same polarity. Remarkably, preliminary results also indicate that charge inversion may be accomplished in amenable systems [17]. These experiments rely upon a novel ESI inlet/flow reactor which is generally applicable to atmospheric pressure ion source instruments. It has also been applied to ion-molecule reactions [18], and should allow pursuit of a new range of fundamental studies.

\section{Experimental}

The ESI source and the mass spectrometer employed in these studies have been described previously $[19,20]$, but a new capillary interface (Figure 1) replaced the nozzle inlet design used in our earlier work [8, 19-22]. This device, a variation upon the glass capillary inlet developed by Whitehouse et al. [23] for ESI, was fabricated in the shape of a " $Y$ " from three $6 \mathrm{~cm}$ lengths of $0.75 \mathrm{~cm}$ o.d., $0.15 \mathrm{~cm}$ i.d. precision bore glass tubing. The two arms of the "Y-tube" were attached at a $60^{\circ}$ angle, providing two inlets that enabled charged species, formed from spatially sepa- 


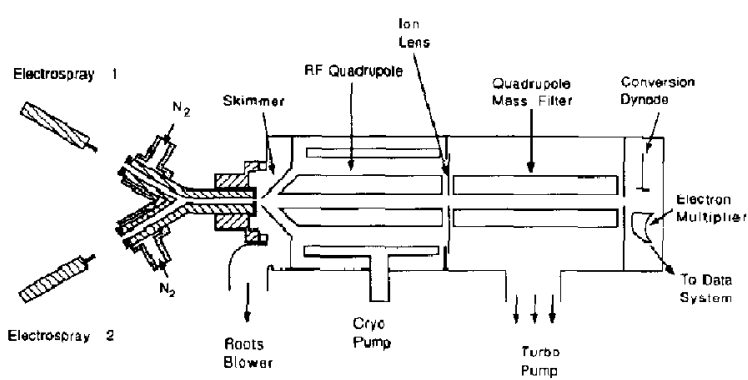

Figure 1. Diagram of the ESI interface incorporating a Y-shaped capillary inlet/reactor. (Not drawn to scale.)

rated ion sources, to be merged. An electrically conductive silver coating was deposited on each of the three ends of the Y-tube reactor to allow the elestric fields at the capillary inlets and outlet to be independently defined. The skimmer, located downstream of the capillary interface, was held at ground potential. In some experiments, metal apertures $(0.4-1.0 \mathrm{~mm}$ i.d.) were positioned over the inlets to reduce the gas flow into the vacuum system and pressure in the reaction region.

Studies were also performed with a stainless steel capillary reactor [9]. Metal $Y$-tubes were fabricated from three $6 \mathrm{~cm}$ lengths of $0.16 \mathrm{~cm}$ o.d., $0.10 \mathrm{~cm}$ i.d. tubing silver-soldered to a stainless stcel post drilled with a Y-shaped channel. The Y-tube reactor was biased from $0-500 \mathrm{~V}$ relative to the skimmer with a high voltage power supply.

For these studies, ESI droplet desolvation was accomplished in one of two ways. The glass capillary employed either a warm, countercurrent flow of $\mathrm{N}_{2}$ $\left(80^{\circ} \mathrm{C}\right)$ and/or an auxiliary heating element which warmed the capillary to $70-200^{\circ} \mathrm{C}$. The countercurrent $N_{2}$ was delivered to each inlet of the $Y$-tube in the annular space enclosed by a brass "tee" sleeved over the glass capillary tubing. The tees were electrically isolated from the inlet electrodes and could be biased separately to enhance ion transmission into the capillary. For the metal reactor, desolvation was promoted by electrical heating $[24,25]$. Currents from $0-20 \mathrm{~A}$ were applied across one arm and the base of the inlet/flow reactor. The other arm was heated with a separate supply, in parallel with the same current supply, or was left unheated, depending upon the particular experiment. Very little heat transfer uccurred between heated and unheated portions of the capillary. For some of the metal capillary studies a transverse flow of $\mathrm{N}_{2}\left(80^{\circ} \mathrm{C}\right)$ was also added to assist in desolvation. Capillary temperatures were indicated by a chromel alumel thermocouple. Optimum settings for capillary temperature and capillary-skimmer bias depended upon whether one or both inlets was open and upon the capillary or aperture i.d. Larger i.d.s required higher capillary temperatures and/or higher capillary-skimmer biases for optimum analyte sensitivity.

The studies reported here employed three different modes of operation: single ESI source, dual ESI sources ( + and - polarities), and ESI along with an atmospheric pressure discharge source $(+/-,-/+$, or $+/+)$. Our methanol liquid sheath ESI source and its typical operating parameters have been described [20-22]. The discharge source consisted of a $5 \times$ $10^{7}$ ohm current-limiting resistor in series with a stainless steel needle. Discharges were struck in air between the inlet electrode and the needle, positioned $1-4 \mathrm{~mm}$ in front of the electrode. Voltages ranging from $2-5 \mathrm{kV}$ were applied to the needle, and discharge currents, measured by an internal ammeter in the high voltage power supply, were varied from 10-100 $\mu \mathrm{A}$.

In the single source mode, an ESI source sprayed into one inlet arm while the other unused inlet arm was either left open to atmospheric pressure or sealed. Measurements from a thermocouple gauge, off-axis from the molecular beam, indicated that the pressure in the first differentially pumped region was generally $\sim 2$ torr with both inlet arms open, and $\sim 1.3$ torr with one inlet sealed. The single source mode was also used to explore ion-molecule chemistry with an ESI source positioned at one inlet arm, while the second inlet delivered neutral reactant gas [18]. Dual source studies employed either a positively biased ESI source and a negative discharge in air, a negatively biased ESI source and a positive discharge in air, or positively and negatively biased ESI sources. Additional studies were performed with two positive polarity sources. Comparisons between dual and single source operation were made by switching on and off the high voltage bias on either source, while maintaining constant all other parameters. Thus, the interface pressure was always the same for the comparisons. The two sources were electrically shielded from each othcr by a grounded aluminum sheet. The discharge source was occasionally displaced radially from the capillary inlet, preventing ion introduction, to confirm that observations attributed to ion-ion interactions were not artifacts induced by the discharge's electric field, and actually depended on the presence of discharge ions.

Biochemical samples were obtained from Sigma Chemical Company (St. Louis, MO), except for oligodeoxyadenylic acid (P. L. Biochemical, Milwaukee, WI). The samples were used without further purification. Analyte solutions for negative ion electrospray were prepared in deionized water or deionized water with 1-3\% ammonium hydroxide, while solutions for positive ion electrospray were preparcd in deionized water with $5 \%$ acetic acid.

\section{Results and Discussion}

\section{Operation with ESI and Discharge Sources of Opposite Polarities}

Atmospheric pressure ionization mass spectrometry and ion mobility studies have determined that $\mathrm{O}_{2}^{-}\left(\mathrm{H}_{2} \mathrm{O}\right)_{n}$ clusters are the major reactant ions gener- 
ated by negative ion discharge sources in air [26]. Negative ion mass spectra confirmed their generation in our corona discharge source, showing $\mathrm{O}_{2}^{-}\left(\mathrm{H}_{2} \mathrm{O}\right)_{n}$ cluster ions with $\mathrm{n}=4-12$ at a capillary outletskimmer (OS) bias of $-160 \mathrm{~V}$. [The OS bias refers to the potential applied between the grounded skimmer and the metallized outlet (exit) of the capillary tubing.] The observed cluster distributions do not necessarily reflect the true ion composition inside the capillary inlet/reactor, however, due to the opposing effects of clustering in the supersonic expansion at the capillary reactor outlet and collision-activated dissociation (CAD) in the OS region [27].

ESI of equine cytochrome $c\left(M_{r} 12,360\right)$ with an OS bias of $+365 \mathrm{~V}$ and a $180^{\circ} \mathrm{C}$ glass capillary yields the $19+$ to $\sim 9+$ multiply protonated molecules, as illustrated in the upper spectrum of Figure 2. The lower spectrum was obtained under the same conditions, but with negative ions from the discharge source $(20 \mu \mathrm{A})$ introduced into the second inlet arm. Operation of the discharge attenuates the highest charge states, while increasing the intensities of the $[\mathrm{M}+$ $9 \mathrm{H}]^{9+},[\mathrm{M}+10]^{10+}$, and $[\mathrm{M}+11 \mathrm{H}]^{11+}$ ions, leading to a shift in the charge state maximum of about two charges. Approximately $70 \%$ attenuation of the total positive ion signal was observed with the discharge "on." Because this estimate does not take into account the reduced quadrupole transmission and detection efficiency at higher mass-to-charge ratio (lower charge), it may overestimate any actual "loss" in ion signal. Employing larger discharge currents leads to greater shifts in the charge state distribution, and also greater reductions in signal levels; for example, in shifting the cytochrome $c$ charge state maximum down to the $10+$ state with a $100 \mu \mathrm{A}$ negative discharge current, we obtained less than $1 \%$ of the discharge "off" signal (sum of intensities from $\mathrm{m} / \mathrm{z} 500$ to 1900). Because of the large signal losses, we could not determine whether even larger discharge currents would shift the charge state maximum below the $[\mathrm{M}+10 \mathrm{H}]^{10+}$ charge state. Factors contributing to the signal loss will be discussed later. For a fixed OS bias, increases in the discharge current also lead to increases in peak widths. As will be explained subsequently, we attribute the increased peak width apparent with the discharge operating to increased solvation of the multiply protonated analyte molecules.

Similar shifts to lower charge states accompanied discharge operation when the 26 residue peptide, melittin $\left(\mathrm{M}_{\mathrm{r}}\right.$ 2846) was sprayed into the glass capillary inlet/reactor at an OS potential of $+230 \mathrm{~V}$ and a capillary temperature of $180^{\circ} \mathrm{C}$, as shown in Figure 3 . In the absence of the negative discharge, the $3+$ to $6+$ multiply protonated molecules were the primary ions detected [21, 22]. Operating the corona discharge simultaneously $(70 \mu \mathrm{A})$ attenuated the $[\mathrm{M}+6 \mathrm{H}]^{6+}$ and $[\mathrm{M}+5 \mathrm{H}]^{5+}$ charge states, while enhancing the intensity of the $[\mathrm{M}+3 \mathrm{H}]^{3+}$ charge state. (At higher detector sensitivities, enhancement of the $[\mathrm{M}+2 \mathrm{H}]^{2+}$ intensity was also apparent.) The total positive ion
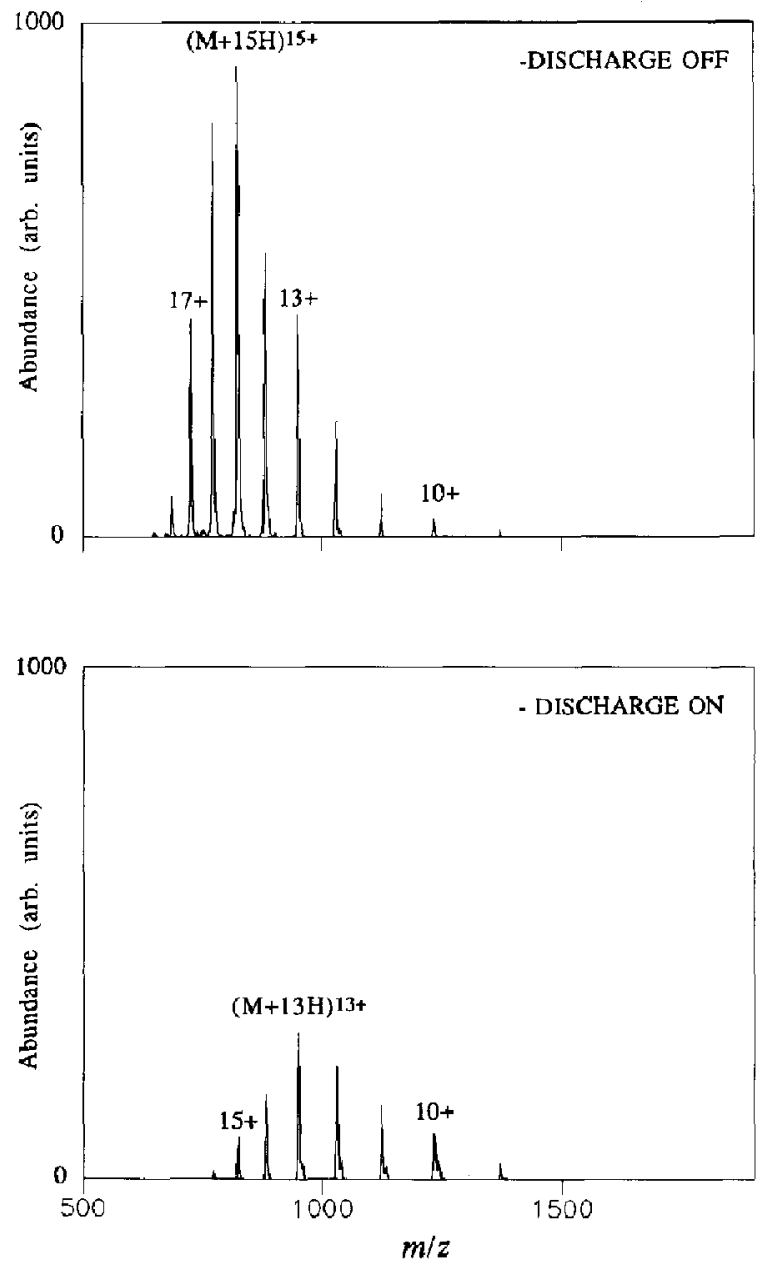

Figure 2. ESI mass spectra for horse heart cytochrome $c\left(\mathbf{M}_{r}\right.$ 12,360) obtained without (top) and with (bottom) the negative discharge in air. Both spectra are plotted on the same intensity scale.

signal (sum of ion intensities from $m / z 400$ to 1500) showed a loss of approximately $40 \%$ with the discharge source operating. Increased solvation of protonated melittin molecules under discharge operation was apparent at lower capillary temperatures ( $\leq$ $\left.120^{\circ} \mathrm{C}\right)$.

When equine myoglobin $\left(M_{r} 16,951\right)$ was sprayed as a positive ion, the total ion signal loss inflicted by operation of the discharge appeared to be more severe than for the two previous examples, as shown in Figure 4. With a $20 \mu \mathrm{A}$ negative discharge current, $+335 \vee$ OS bias, and $200^{\circ} \mathrm{C}$ glass capillary, the maximum in the myoglobin charge state distribution shifted from the $19+$ to the $14+$ charge state. Approximately $97 \%$ of the total positive ion signal was lost. For the wide range of experimental conditions evaluated, a shift in charge state maximum always corresponded to a significant loss in total positive ion signal.

That increased ion solvation accompanies discharge 

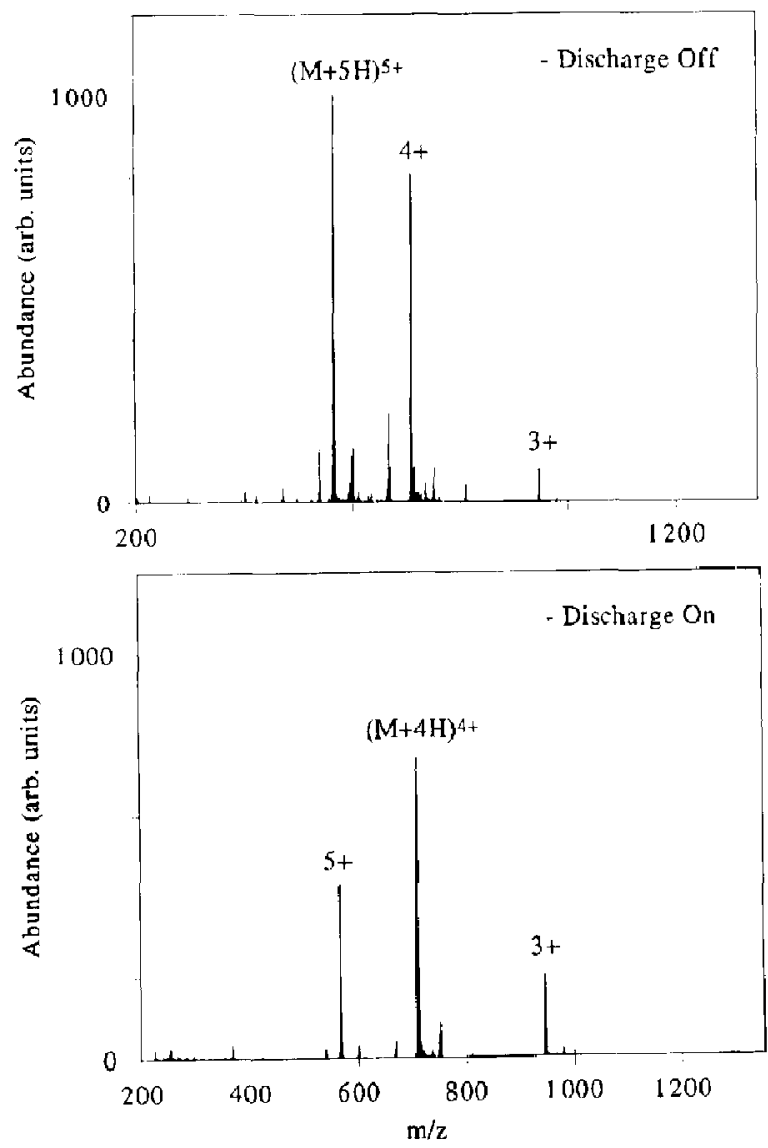

Figure 3. ESI mass spertra of melittin (M, 2846) obtained without (top) and with (bottom) the neygative discharge in air. Both spectra employ the: same intensity scale.

operation is understandable, because the corona discharge source is expected to generate the solvated ions $\mathrm{O}_{2}^{-}\left(\mathrm{H}_{2} \mathrm{O}\right)_{\pi}$, rather than bare $\mathrm{O}_{2}^{-}$. Even though the discharge source itself may generate oxygen anions with relatively few coordinate water molecules, the ESI process and the capillary interface do not completely exclude solvent molecules, ensuring that there are plenty of $\mathrm{H}_{2} \mathrm{O}$ and $\mathrm{CH}_{3} \mathrm{OH}$ molecules available downstream for clustering about $\mathrm{O}_{2}^{-}$and $\mathrm{O}_{2}^{-}\left(\mathrm{H}_{2} \mathrm{O}\right)_{n}$ anions as the two gas streams merge. Thus, it is feasible that ion-ion interactions with solvated anions could transfer solvent molecules to the multiply protonated analyte. The present results suggest that this solvent transfer occurs highly efficiently.

To probe this discharge-dependent solvation behavior more carefully, we examined the peptide bradykinin $\left(M_{r} 1060\right)$ by using a metal $Y$-tube reactor at a temperature of $250^{\circ} \mathrm{C}$, an OS bias of $+280 \mathrm{~V}$, and an $8 \mu \mathrm{A}$ discharge current. ESI of bradykinin yields primarily $[\mathrm{M}+2 \mathrm{H}]^{2+}$ and $[\mathrm{M}+\mathrm{H}]^{+}$ions, although a small amount of $[\mathrm{M}+3 \mathrm{H}]^{3+}$ was observed. Figure 5 illustrates the increased $\mathrm{H}_{2} \mathrm{O}$ solvation accompanying discharge operation. The $[\mathrm{M}+2 \mathrm{H}]^{2+}$ ion signal intensity is reduced by about $95 \%$ with the discharge
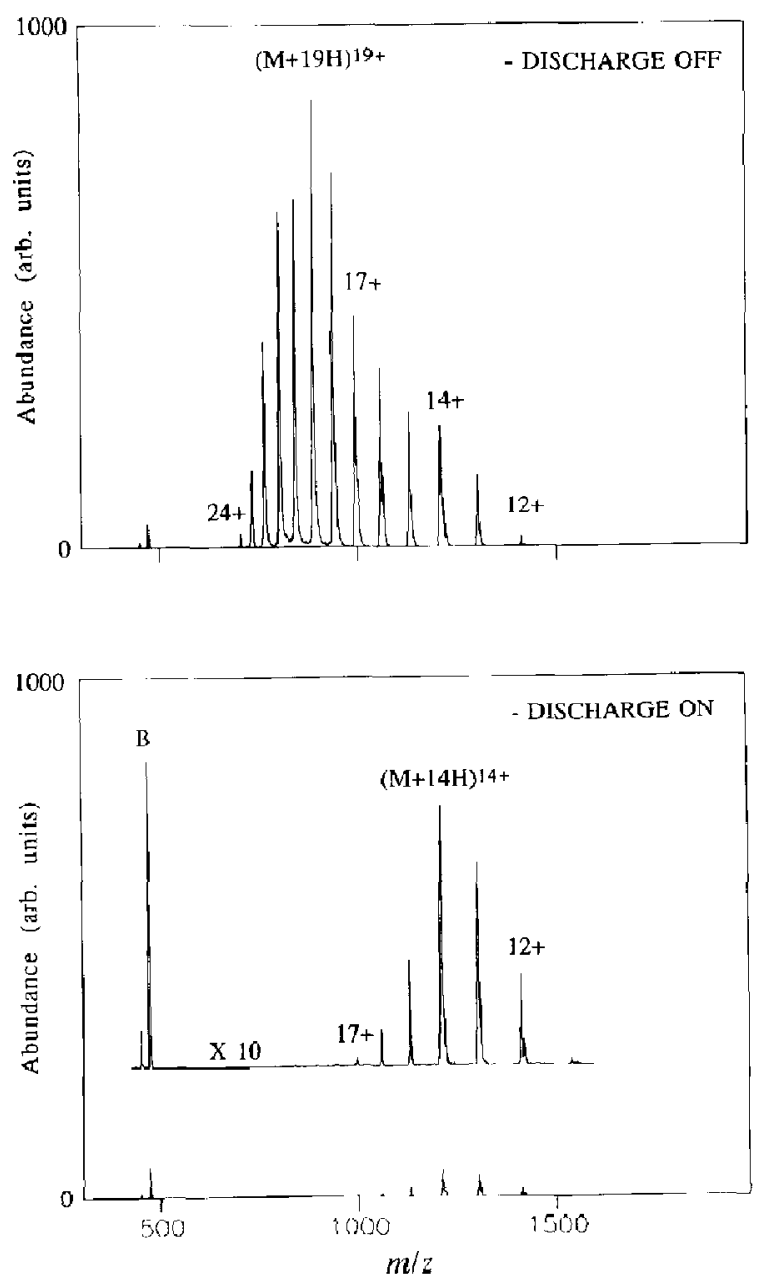

Figure 4. ESI mass spectra of equine myoglobin $\left(M_{r}\right.$ 16,951) without (top) and with (bottom) the negative discharge in operation. Both figures are plotted on the same intensity scale. $B=$ background from the sheath solvent.

on, while the $\left[\mathrm{M}+2 \mathrm{H}+12 \mathrm{H}_{2} \mathrm{O}\right]^{2+}$ ion signal is about five times more intense. The increase observed in highly solvated $[\mathrm{M}+2 \mathrm{H}]^{2+}$ ions appears roughly consistent with the attenuation of $[\mathrm{M}+3 \mathrm{H}]^{3+}$ ions. At higher OS biases (e.g., $+340 \mathrm{~V}$ ), collisional activation downstream in the OS region leads to evaporation of essentially all of the water from the doubly charged ions, leaving only $[\mathrm{M}+2 \mathrm{H}]^{2+}$ and very small contributions from $[\mathrm{M}+\mathrm{H}+\mathrm{Na}]^{2+},[\mathrm{M}+2 \mathrm{Na}]^{2+}$, and $[\mathrm{M}$ $\left.+2 \mathrm{H}+\mathrm{nCH}_{3} \mathrm{OH}\right]^{2+}(\mathrm{n}=1-3)$ ions in the $\mathrm{m} / \mathrm{z}$ 500-700 range with the discharge off. (Note that methanol is employed as the sheath solvent in the ESI source.) With the discharge on, the $\mathrm{IM}+2 \mathrm{H}+$ $\left.\mathrm{nCH}_{3} \mathrm{OH}\right]^{2+}$ ions double or triple in intensity. It seems likely that methanol, released by droplet evaporation in the capillary, clusters with the discharge-produced anions and is subsequently transferred to the analyte cations, presumably during charge transfer. The signal losses noted earlier for discharge operation preclude a 

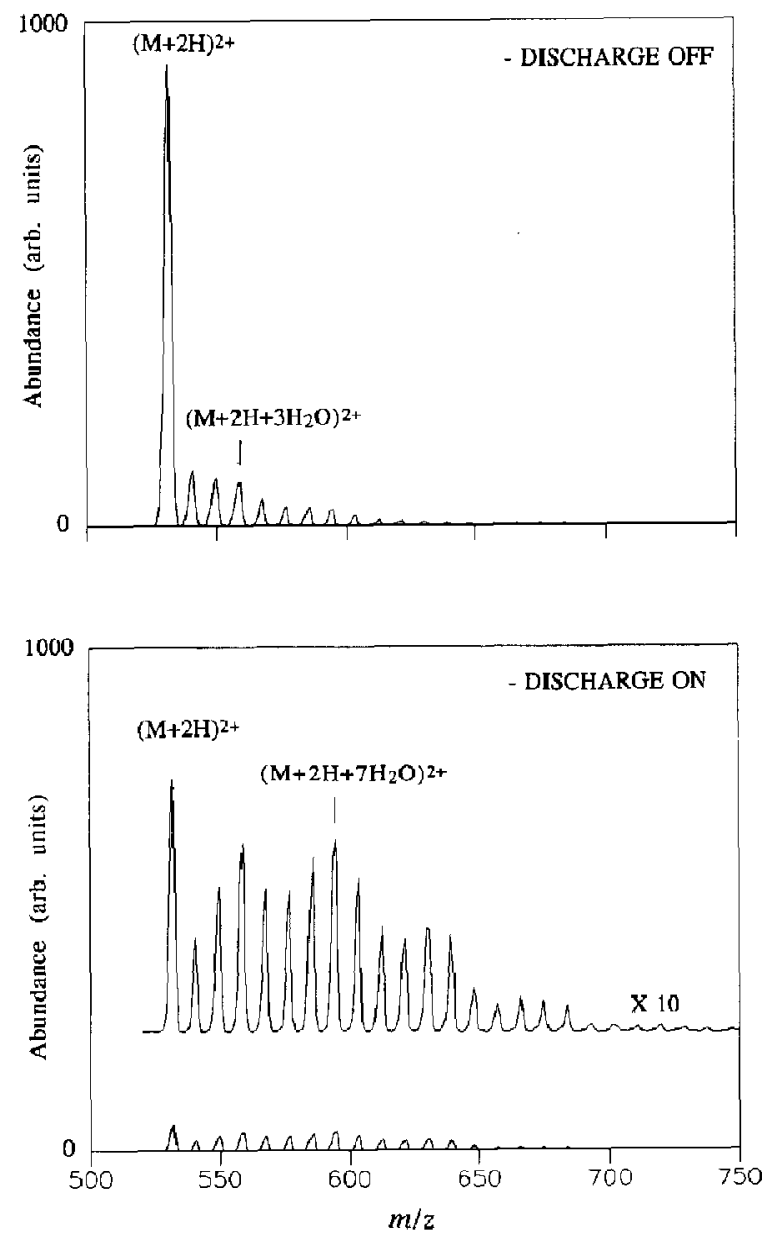

Figure 5. Increased $\mathrm{H}_{2} \mathrm{O}$ solvation accomparying discharge operation. Positive ion ESI mass spectra of bradykinin ( $\left.M_{r} 1060\right)$ without (top) and with (bottom) negative discharge operation. Both spectra are plotted on the same intensity scale.

complete evaluation of the correlation between the increase in solvation for low charge state cations and the attenuation of total positive ion signal.

Evaporation of attached solvent molecules is likely to play a crucial role in dissipating the excess energy released by ion-ion reactions, thus avoiding the dissociation processes which might otherwise accompany them. Initially we wondered if the products of ion-ion reactions might emerge with fewer solvent adducts than their precursors because of evaporation. That hypothesis is not supported by the present experiments. However, future experiments employed improved ion desolvation prior to the $Y$-tube inlet/reactor, and which independently vary capillary temperatures in all three regions of the $Y$-tube, may provide additional insights.

The results obtained in the discharge reactions were quite sensitive to experimental parameters. For example, the shift in charge state maximum and reduction in total ion signal depended on the molecule studied and on the magnitude of the discharge current, needleinlet spacing, OS bias, and the inlet aperture size. These parameters are interrelated, governing the number of positive and negative ions delivered to the inlet/reactor, the pressure in the capillary reactor OS region, and the amount of solvent association induced by discharge operation. Comparisons between spectra obtained with the discharge "on" and "off" were always performed at constant OS bias, but selecting the appropriate value for that bias was often critical for observing the increased intensity that the lower charge states experienced with the discharge on. If the OS bias was set too low, increased ion solvation was the dominant effect, and no $[\mathrm{M}+\mathrm{nHH}]^{\mathrm{n}+}$ charge state intensities were enhanced by discharge operation, although the integrated intensity over all solvent peaks (e.g., $[M+$ $\left.\mathrm{nH}+\mathrm{mH}_{2} \mathrm{O}\right]^{\mathrm{n}+}, \mathrm{m} \geq 0$ ) of the lower charge state ions were often enhanced. That is, while the $[\mathrm{M}+\mathrm{nH}]^{\mathrm{n}+}$ abundance may not have increased during discharge operation, the sum of $[\mathrm{M}+\mathrm{nH}]^{\mathrm{n}+},[\mathrm{M}+\mathrm{nH}+$ $\left.\mathrm{H}_{2} \mathrm{O}\right]^{\mathrm{n}+},\left[\mathrm{M}+\mathrm{nH}+2 \mathrm{H}_{2} \mathrm{O}\right]^{\mathrm{n}+}, \ldots$, and $[\mathrm{M}+\mathrm{nH}+$ $\left.\mathrm{mH}_{2} \mathrm{O}\right]^{\mathrm{n}+}$ abundances would often be observed to increase. The selected OS bias also affected the location of the observed maximum in the charge state distribution. For the equine cytochrome $c$ study at $O S=+365$ $\mathrm{V}$, then $9+$ to $11+$ charge states increased in abundance with the discharge in uperation, but at $+250 \mathrm{~V}$ the increase was seen only in the $9+$ to $10+$ states and the $[\mathrm{M}+11 \mathrm{H}]^{11+}$ ion was strongly attenuated. At OS $=+250 \mathrm{~V}$ the full width half-maximum of the $10+$ and $11+$ charge state peaks were about 10 times those at $O S=+365 \mathrm{~V}$, reflecting increased solvation. Hence, observations are quite dependent on the OS potential selected, and higher OS biases generally lead to better sensitivities for lower charge states and better desolvation (although too high of a bias can still induce dissociation).

Increased relative abundance of the mass 98 adduct was also observed to accompany discharge operation for some samples, for example, myoglobin and cytochrome $c$. Chowdhury et al. [10] have shown that this common adduct often arises from sulfate or phosphate contamination. Because the discharge is unlikely to be the source of sulfate- or phosphate-related anions, the increased adduct contributions are probably another consequence of the increased solvation under discharge operation. Counterion removal by collisional activation is expected be be less effective for increasingly solvated molecules.

Although the total ion signal losses observed in the previous examples arise in part from the reduction in charge state coupled with the mass spectrometer's reduced transmission efficiency at higher mass-tocharge ratio, other loss mechanisms may also contribute. The optimum OS bias for detection of high charge states (without dissociation) is generally lower than the optimum OS bias for low charge state detection. (Ideally, one would like to ramp the OS bias as a function of mass-to-charge ratio, provided that CAD 
products from higher charge state ions are insignificant or could be differentiated from low charge state components.) Because these studies held the OS bias constant for comparison with and without the discharge, there is some reduction in detection efficiency for lower charge state ions. The increased solvation observed to accompany discharge operation probably also shares responsibility for the signal losses, because the analytc ions which emerge from the capillary inlet/reactor have widely varying amounts of water or methanol attached. Consequently, the ion signals for a single charge state are spread over a large mass-to-charge ratio range. Operating at higher OS biases reduces the extent of solvation, although in some cases the bias voltage is limited by dielectric breakdown in the OS region. Also, the effect of an elevated OS bias on a heavily solvated molecule (desolvation) must be balanced by its effect on a nonsolvated one (dissociation). In cases where the range of analyte ion solvation is extensive, mass spectrometry may not be capable of quantitatively comparing analyte signals with and without the discharge.

Now we return to the issue of dissociation, but from a slightly different perspective, one in which the analyte ions are deliberatcly fragmented at high OS biases to study the effect of discharge operation. Figure 6 illustrates ESI mass spectra obtained for ovine myoglobin $\left(\mathrm{M}_{\mathrm{r}} 16,923\right)$ at $\mathrm{OS}=+560 \mathrm{~V}$ with a glass capillary at $180^{\circ} \mathrm{C}$, both with and without discharge operation. The top spectrum is a typical CAD mass spectrum for myoglobin [8a]. Clearly, operation of the negative discharge reduces the extent of dissociation. The reductions in charge state and in fragmentation which are observed upon operation of the negative discharge are consistent with an ion-ion charge site neutralization reaction occurring in the high-pressure capillary after the two ion streams have merged, but before the OS region where dissociation is induced. Because higher charge states are preferentially dissociated at elevated $O S$ biases due to their higher translational energies $[8,22,28]$, any reaction reducing the number of highly charged ions in the inlet/reactor leads to a reduction in dissociation downstream in the OS region. Behavior similar to Figure 6 has also been observed for melittin at high OS biases. This experiment differs from the ion-molccule studies of McLuckey et al. [2\%] which probed the reactivities of melittin CAD products. Those studies generated and isolated $C A D$ products prior to reaction, while in these studies we attempt to generate CAD products after reaction. Conceivably, product reactivities could be examined in our apparatus (albeit without reactant selection) by heating the ESI inlet arm to higher temperatures to thermally induce dissociation $[24,25]$ prior to the ion-ion interaction region.

Small discharge currents affected the spectra of highly charged proteins much more than the spectra of less highly charged peptides. For example, the melittin spectrum (see Figure $3 \mathrm{~b}$ ) was obtained with a $70 \mu \mathrm{A}$
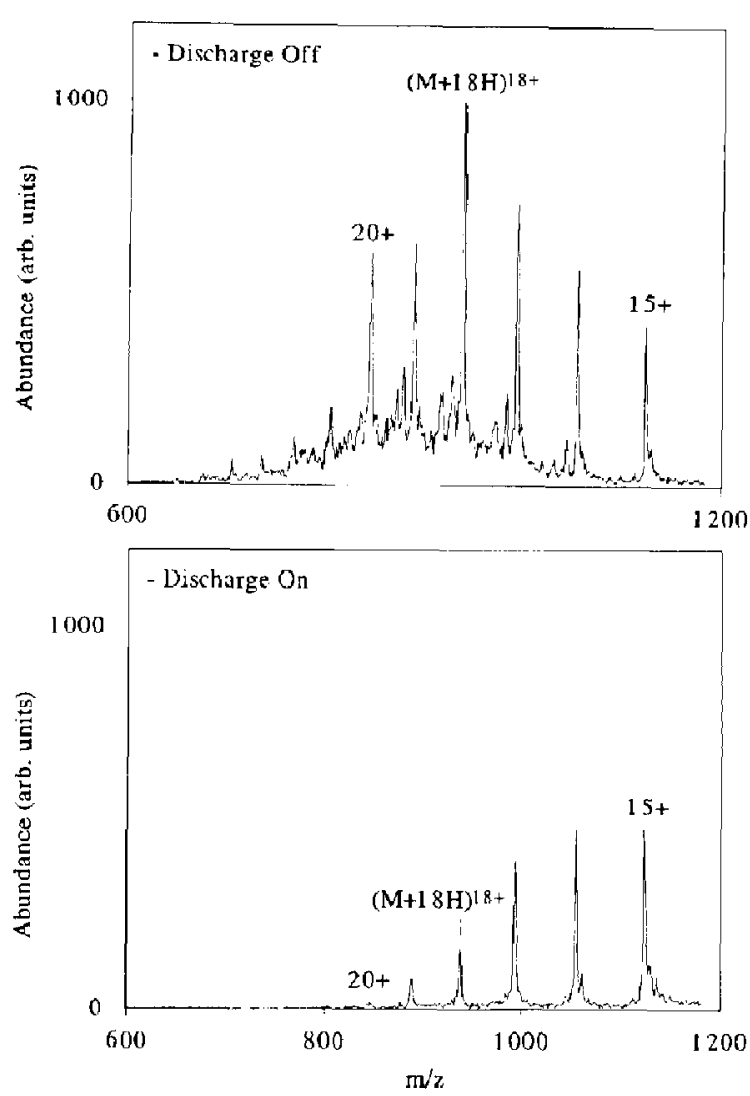

Figure 6. (Top) ESI mass spectra of ovine myoglobin $\left(\mathbf{M}_{\mathbf{r}} \mathbf{1 6 , 9 2 3 )}\right.$ at $\mathrm{OS}=+560 \mathrm{~V}$ with only the ESI source operating. (Bottom) ESI mass spectra of myoglobin at $O S=+560 \mathrm{~V}$ with the negative discharge in operation. The figures are plotted on the same intensity scale.

negative discharge current, while a discharge current of only $20 \mu \mathrm{A}$ was used to obtain the cytochrome $c$ spectrum illustrated in Figure $2 b$. These differences are illustrated further in the ESI mass spectra for a mixture of melittin $\left(7 \times 10^{5} \underline{\mathrm{M}}\right)$ and equine cytochrome $\mathrm{c}$ $\left(5.7 \times 10^{-5} \underline{\mathrm{M}}\right)$ at $\mathrm{OS}=+400 \mathrm{~V}$ and a metal capillary at $250^{\circ} \mathrm{C}$, as illustrated in Figure 7. [Note that because the spectra obtained in Figure 7 employed metal apertures positioned over the inlets that differed from those used to obtain Figures 2 and 3 (see Experimental), as well as different needle-inlet spacings on the discharge source, the Figure 7 spectra are not directly comparable to the spectra in Figures 2 and 3.] Although operation of the $13 \mu \mathrm{A}$ negative discharge attenuated the cytochrome $c$ signals by approximately $70 \%$ (sum of intensities $14+$ to $18+$ charge states), as illustrated in Figure 7 , the melittin ion signals were attenuated by only $30 \%$ (sum of intensities $3+, 4+$, and $5+$ charge states). The melittin $[\mathrm{M}+4 \mathrm{H}]^{4+}$ ion (peak intensity offscale in both panels of Figure 7) is approximately 3.3 times as abundant as the $[\mathrm{M}+$ $5 \mathrm{H}]^{5+}$ ion. Apparently, the extent of multiple charging affects the reactivity of the ions in the capillary inlet/reactor, consistent with anticipated relative cross 

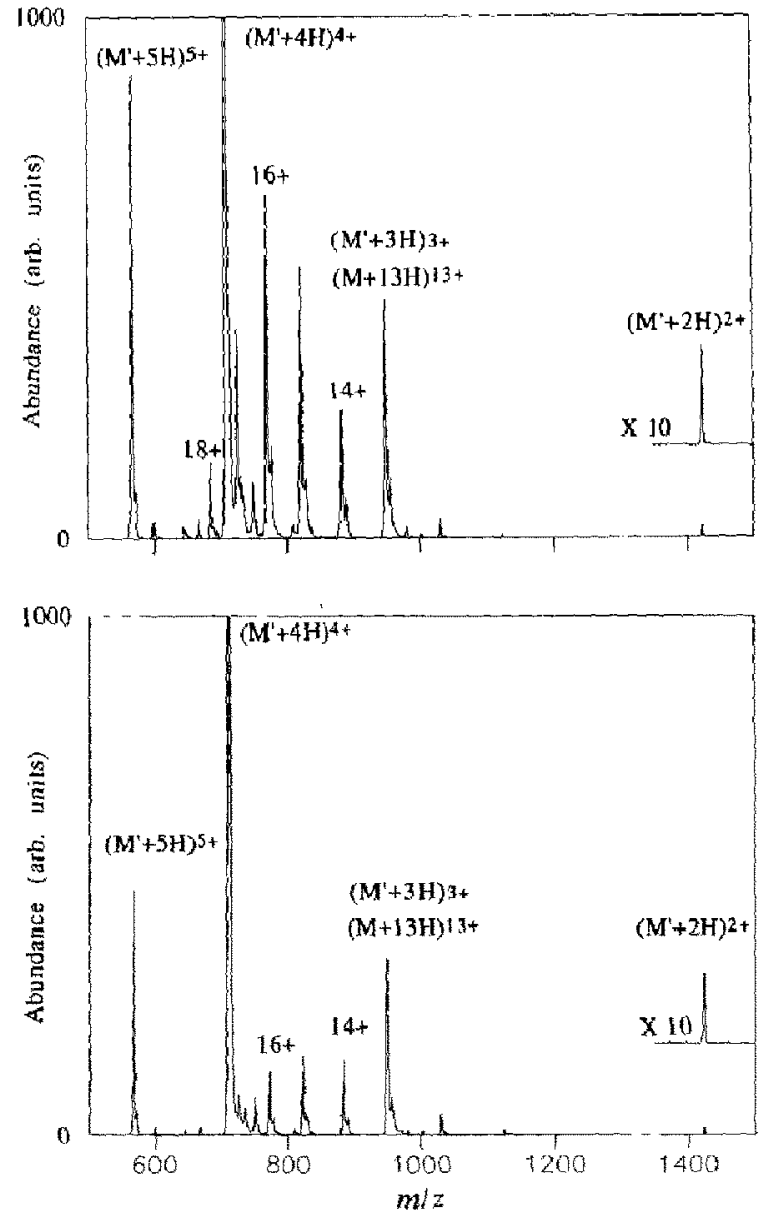

Figure 7. (Top) ESI mass spectra of a mixhare of equine cytochrome $t$ and melittin with OS $=+400 \mathrm{~V}$. (Bothom) As above, but with operation of a $13 \mu \mathrm{A}$ negative discharge in air. The spectra are plotted on the same intensify scale. $M^{\prime}=$ melittin; $M=$ cylochrome $c$.

sections for ion-ion processes. The differing responses of melittin and cylochrome $c$ to discharge operation provide a unique approach to mixture analysis. Under these inlet/reactor conditions, an OS bias of $+550 \mathrm{~V}$ is sufficient to induce dissociation in melittin, but not in the cytochrome $c$; hence, the $m / z \quad 1000-1500$ region of the ESI mass spectrum (Figure 8, top) is composed of melitín product ions, cytochrome $c[\mathrm{M}+11 \mathrm{H}]^{11+},[\mathrm{M}$ $+10 \mathrm{H}]^{10+}$, and $[\mathrm{M}+9 \mathrm{H}]^{9+}$ ions, and melittin $[\mathrm{M}+$ $2 \mathrm{H}]^{2+}$ ions. Operation of the $13 \mu \mathrm{A}$ negative discharge under these conditions attenuates or even eliminates the melittin product ions, enhances the abundances of the cytochrome $c[\mathrm{M}+11 \mathrm{H}]^{1+}$ and $[\mathrm{M}+10 \mathrm{H}]^{10+}$ ions, and decreases the abundance of the melitin [M $+2 \mathrm{H}^{2+}$ ion.

Up to now we have focused exclusively on the negative discharge/positive ESI source combination. We have also studied the opposite combination: positive discharge/negative ESI. Positive discharges are known to produce $\left(\mathrm{H}_{2} \mathrm{O}\right)_{n} \mathrm{H}^{+},\left(\mathrm{CH}_{3} \mathrm{OH}\right)_{n} \mathrm{H}^{+}$, or proto-
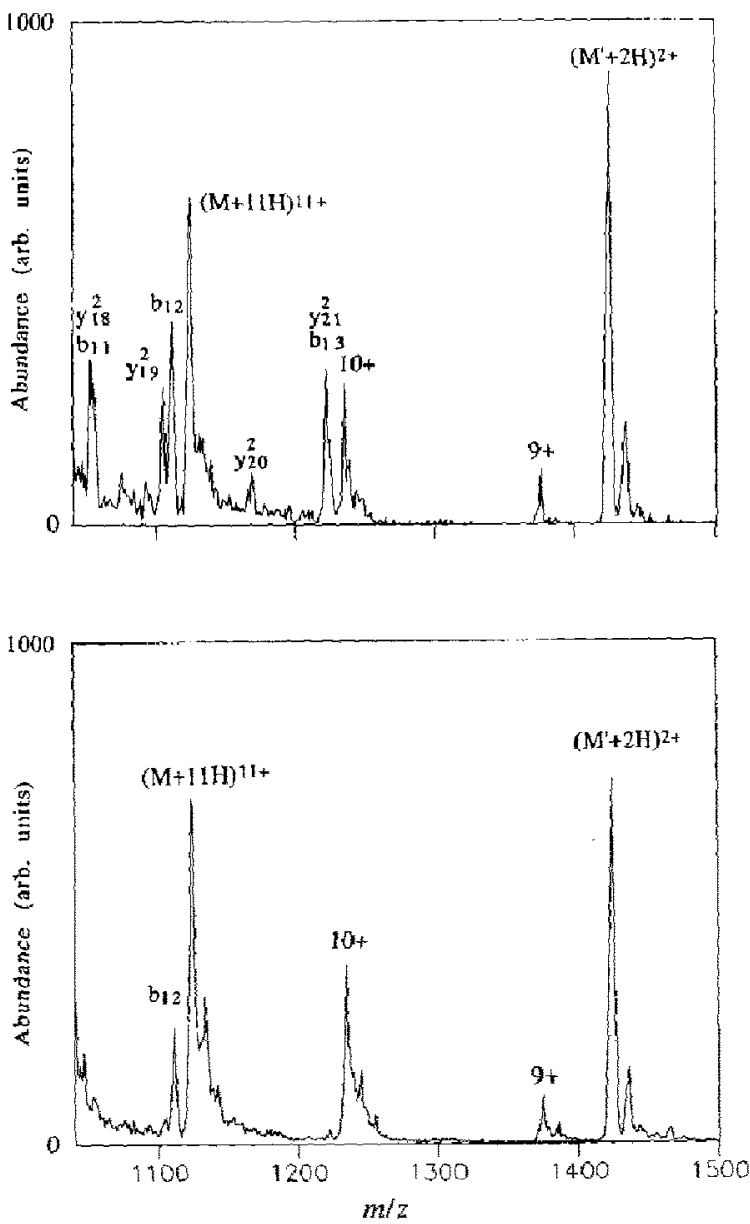

Figure 8. ESI mass spectra of a sytochrome c/melittin mixture without (top) and with (bottom) the negative discharge. os = $+550 \mathrm{~V}$. Both spectra are plotted on the same intensity scale. $\mathrm{M}^{\prime}=$ melittin; $\mathrm{M}=$ cytachrorne $c$. All labeled product lons arise from melittin.

nated mixed water/methanol clusters $[27,30]$, thus, they are the most likely cationic reactants for our positive discharge studies. Deprotonated oligodeoxyadenylic acid ( $d(\mathrm{pA})_{3}, \mathrm{M}_{r}$ 957) was employed as the anionic reactant. The negative ESI mass spectra of $\mathrm{d}(\mathrm{pA})_{3}$ with and without operation of the $5 \mu \mathrm{A}$ positive discharge are shown in Figure 9 . Both spectra were obtained with $O S=-265 \mathrm{~V}$, a metal capillary at $230^{\circ} \mathrm{C}$, and are plotted on the same intensity scale. These results bear several similarities to those from the negative discharge/positive ESI studies. First of all, operation of the discharge attenuates the highest charge states species, $[\mathrm{M}-3 \mathrm{H}]^{3-}$ and $[\mathrm{M}-2 \mathrm{H}]^{2-}$, while enhancing the intensity of the low charge state $\left[\mathrm{M}-\mathrm{H}^{-}\right.$. It leads to a loss of total ion signal, although we do not know how much of this loss arises from neutralization of the $\mathrm{d}(\mathrm{pA})_{3}$ ions. Finally, discharge operation reduces the extent of negative ion dissociation by reducing the number of highly charged ions--the ions most likely to undergo dissociation. Facile adenine ion loss, 

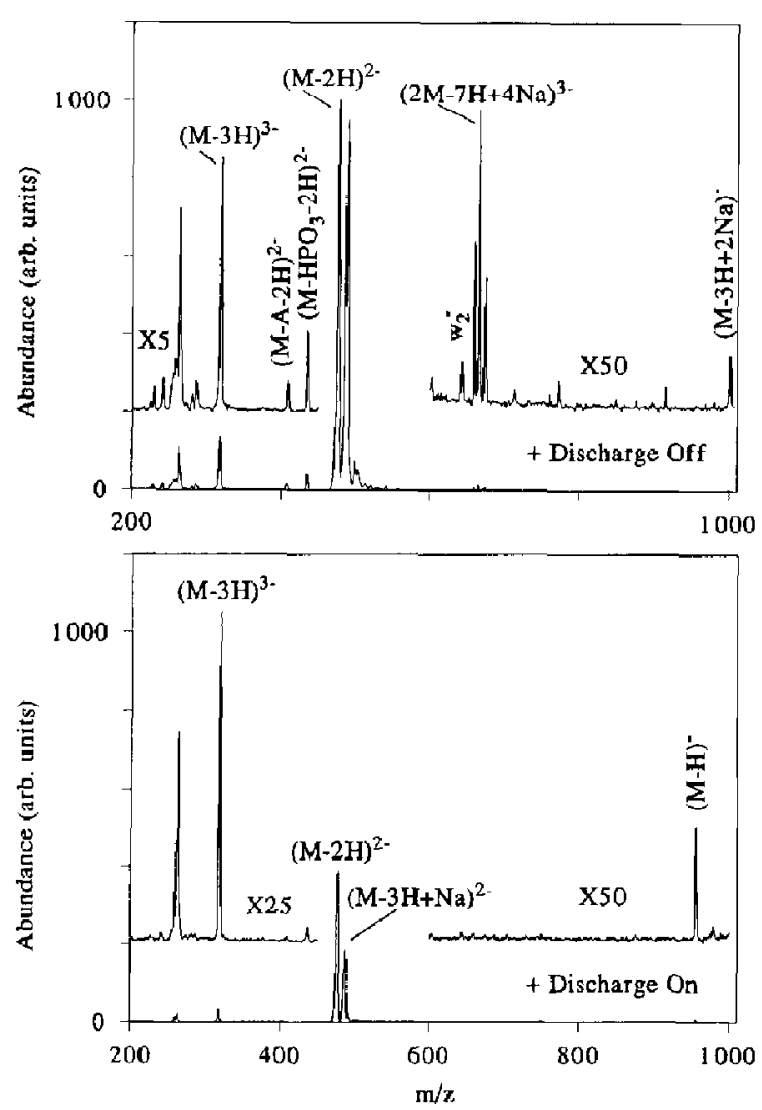

Figure 9. ESI mass spectra of $d(p A)_{3}$ without (top) and with (bottom) operation of a $5 \mu \mathrm{A}$ positive discharge in air. Both spectra were obtained with $O S=-265 \mathrm{~V}$ and are plotted on the same intensity scale. The peaks at $m / z$ 659, 666, and 674 are assigned to triply charged dimer ions of $\mathrm{d}(\mathrm{pA})_{3}$ with 3,4 , and 5 sodium atoms attached, respectively. There may also be a contribution to the dimer ion peak labeled $[2 \mathrm{M}-7 \mathrm{H}+4 \mathrm{Na})^{3-}$ at $m / z$ 666. from $\left(\mathbf{w}_{2}^{-}-\mathrm{H}+\mathrm{Na}\right)^{-}$or $\left(\mathbf{b}_{2}^{-}-\mathrm{H}+\mathrm{Na}\right)^{-}$predicted at $m / z 665$.

noted in a tandem mass spectrometry study of small, multiply charged oligonucleotides [31], is also evident in Figure 9. The ion at $m / z 643$ is attributed to a $\mathbf{w}_{2}^{-}$ product, using the nomenclature proposed by McLuckey et al. [31], and based on their observation that adenine loss was generally followed by cleavage of the $3^{\prime}$ phosphodiester linkage of the sugar from which the adenine was lost. (See Scheme I.) A possible alternate assignment for $m / z 643$ is $b_{2}^{-}$.

The intensity behavior of the sodium adduct ions is particularly informative. Without the positive discharge (Figure 9, top), this sample yielded triply charged $d(p A)_{3}$ as $[M-3 H]^{3-}$ exclusively and doubly charged $\mathrm{d}(\mathrm{pA})_{3}$ as $[\mathrm{M}-2 \mathrm{H}]^{2-}$ and $[\mathrm{M}-3 \mathrm{H}+\mathrm{Na}]^{2-}$ with nearly equal abundances. Singly charged $d(p A)_{3}$ was primarily observed as $[\mathrm{M}-3 \mathrm{H}+2 \mathrm{Na}]^{-}$. Sodium is attached preferentially to lower charged oligonucleotide anions [8b, 16]. Discharge operation altered these relative abundances dramatically. While triply charged $\mathrm{d}(\mathrm{pA})_{3}$ continued to be present as $[\mathrm{M}-3 \mathrm{H}]^{3-}$

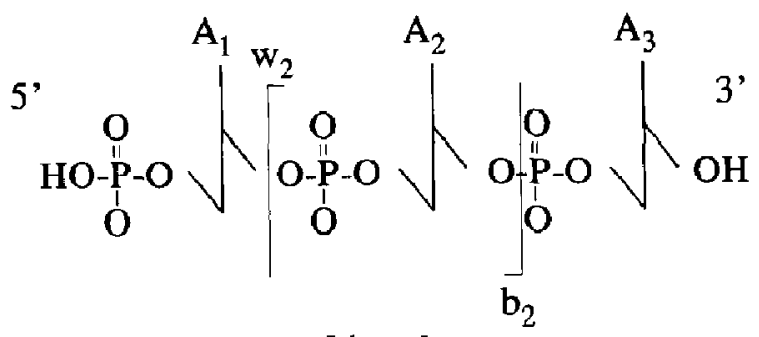

Scheme I.

exclusively, $[\mathrm{M}-2 \mathrm{H}]^{2-}$ became twice as abundant as $[\mathrm{M}-3 \mathrm{H}+\mathrm{Na}]^{2-}$. The monoanion, no longer observed as $[\mathrm{M}-3 \mathrm{H}+2 \mathrm{Na}]^{-}$, was primarily present as $[\mathrm{M}-\mathrm{H}]^{-}$with a small amount of $\left[\mathrm{M}-2 \mathrm{H}+\mathrm{Na}^{-}\right.$. The reduced sodium adduct contributions after reaction suggest that the ions retain some memory of their heritage, because under normal ESI conditions, low charge state anions would be more likely to carry attached sodium than would highly charged anions. Thus, the $[\mathrm{M}-\mathrm{H}]^{-}$anions observed under discharge operation likely arise from proton transfer to $[\mathrm{M}-$ $3 \mathrm{H}]^{3-}$ and $[\mathrm{M}-2 \mathrm{H}]^{2-}$, rather than from direct ESI. The ratio of $[\mathrm{M}-\mathrm{H}]^{-}$to $\left[\mathrm{M}-2 \mathrm{H}+\mathrm{Na}^{-}\right.$in the discharge "on" spectrum suggests that two protons may be transferred under these conditions, supporting our hypothesis that neutralization may contribute significantly to the overall signal loss suffered by $d(p A)_{3}$ under discharge operation. These arguments also suggest that the sodium adduct contributions decreased after reaction because the lower charge state species were more likely to be neutralized. Triply charged dimer ions at $m / z 659,666$, and 674 (with 3,4 , and 5 attached sodium atoms, respectively) vanish with discharge operation, but do not produce the corresponding doubly charged ions at $m / z$ 989, 1000, and 1011 . (Although $[2 \mathrm{M}-6 \mathrm{H}+4 \mathrm{Na}]^{2-}$ would overlap with $\left[\mathrm{M}-3 \mathrm{H}+2 \mathrm{Na}^{-}\right.$at $m / z \quad 1000$, doubly charged dimers at $m / z 989$ and 1011 would not be obscured by singly charged monomers.) Perhaps the excess kinetic energy released in the ion-ion neutralization (after evaporation of any attached solvent) is sufficient to dissociate the dimer, but insufficient to fragment the monomer. Dimeric products from multiple proton transfers may be present at higher mass-tocharge ratio.

Aside from their relevance to ion-ion reaction studies, these experiments are also of interest for their potential utility in shifting charge state distributions. Applications where a shifted charge distribution is desirable include, for example, production of lower charge state precursors for tandem mass spectrometry comparisons of different charge states. Our experience suggests that the ion-ion reactions studied to date for this purpose are not as easy to control and appear to lead to greater signal losses than do ion-molecule reactions $[18,29,32-34]$.

At present we have no evidence upon which to distinguish the specific reaction(s) occurring between 
the discharge anions and the $[\mathrm{M}+\mathrm{nH}]^{\mathrm{n}+}$ cations. Proton transfer to $\mathrm{O}_{2}^{-}$or solvated $\mathrm{O}_{2}^{-}$to generate $\mathrm{OOH}$ is only one possibility. For the positive discharge/ negative ESI combination, it appears reasonable that the relevant reaction is proton transfer from $\left(\mathrm{H}_{2} \mathrm{O}\right)_{n} \mathrm{H}^{+}$, $\left(\mathrm{CH}_{3} \mathrm{OH}\right)_{\mathrm{n}} \mathrm{H}^{+}$, or $\left(\mathrm{CH}_{3} \mathrm{OH}\right)_{m}\left(\mathrm{H}_{2} \mathrm{O}\right)_{n} \mathrm{H}^{+}$ions to the even electron [M $-\mathrm{nH}]^{\mathrm{n}-}$ anions. At this point in our studies it is difficult to address questions regarding the relevant reaction rates because we are still uncertain of the neutralization and solvation contributions to signal attenuation. A crude estimate performed previously suggested that half lives of $0.1-1 \mathrm{~s}$ might be expected for ion-ion reactions under dual ESI operation [17]. More studies are required to obtain reliable estimates of the relevant reaction rates.

\section{Operation with Dual ESI Sources}

Reaction studies were also undertaken with dual electrospray sources, as in our previous report on charge inversion reactions in fluorescein and adenosine $5^{\prime}$ monophosphale (AMP) [17]. Those studies employed $[\mathrm{M}-\mathrm{H}]^{-}$anions and $\left[\mathrm{M}^{\prime}+\mathrm{nH}\right]^{\mathrm{n}+}$ cations as reactants. We have also investigated several systems reacting multiply charged anions. Figure 10a shows the negative ion mass spectrum of bovine A-chain insulin (oxidized, $M_{r}$ 2532), obtained with only the negative ESI source operating (OS $=-390 \mathrm{~V}$, capillary temperature $=200^{\circ} \mathrm{C}$ ). The sulfonic acid groups on oxidized A-chain insulin are sufficiently acidic to enable a solution of the polypeptide in $\mathrm{H}_{2} \mathrm{O}$ to yield negatively charged insulin. Figure $10 \mathrm{~b}$ illustrates the negative ion mass spectrum obtained when myoglobin cations were introduced through the other inlet. Relative to the A-chain insulin $[\mathrm{M}-4 \mathrm{H}]^{4-}$ charge state, the $[\mathrm{M}-5 \mathrm{H}]^{5-}$ intensily was reduced upon + ESI operation while the $[\mathrm{M}-3 \mathrm{H}]^{3-}$ was enhanced, consistent with the earlier observation that the highest charge states tend to be affected most by ion-ion reaction. For the variety of conditions explored, none of the charge states appeared to increase in absolute abundance with + ESI operation. An over $50 \%$ loss of total ion signal was experienced for discharge operation under the conditions employed in Figure 10. Operation at $O S=$ $-190 \mathrm{~V}$ yielded similar attenuations, but discharge-induced enhancement of the $[\mathrm{M}-3 \mathrm{H}]^{3-}$ relative to [M $-4 \mathrm{H}]^{4-}$ was not abserved. It is not clear how much of the signal attenuation reflects neutralization and formation of $[\mathrm{M}-\mathrm{H}]^{-}$lying outside of our quadrupole's mass-to"charge ratio range. The effect of ion-ion reactions on the positive ion mass spectrum of myoglobin was less pronounced. As in the myoglobin/AMP study [17], only the intensities of myoglobin's highest charge states appeared to be reduced. In a rough comparison, the amount of attenuation of the myoglobin high charge states appeared consistent with the attenuation in Achain insulin, although at this point in our studies uncertainties in the detector's relative responses to positive and negative ions provide some latitude for
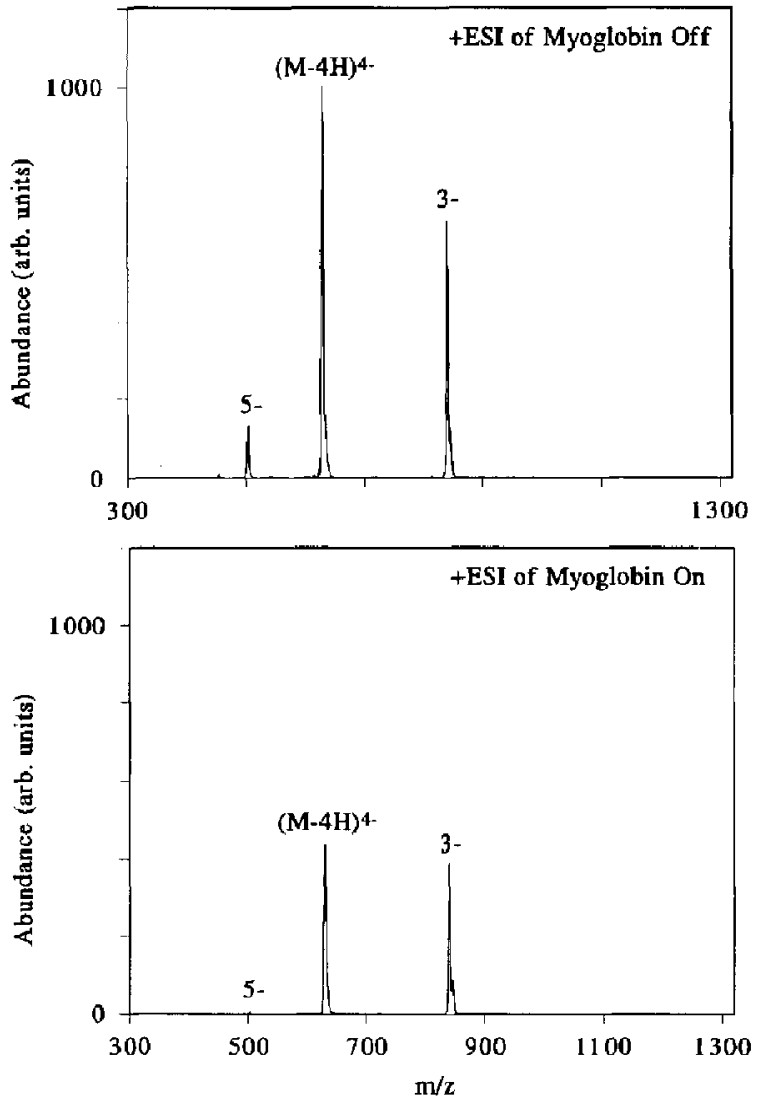

Figure 10. Operation with dual electrospray sources. (Top) ESI mass spectra of oxidized A-chain bovine insulin with only the negative ESI source in operation. (Bottom) ESI mass spectra of A-chain insulin with negative and positive ESI sources in operation. Myoglobin was used for positive ESI. Both spectra are plotted on the same intensity scale.

that comparison. No insulin/myoglobin complexes were observed.

Other studies examined equine myoglobin $[\mathrm{M}+$ $\mathrm{nH}]^{\mathrm{n}+}$ reacting with porcine pepsin $\left[\mathrm{M}^{\prime}-\mathrm{mH}\right]^{\mathrm{m}-}$, myoglobin $[\mathrm{M}+\mathrm{nH}]^{\mathrm{n}+}$ reacting with $\mathrm{d}(\mathrm{pA})_{3}\left[\mathrm{M}^{\prime}-\right.$ $\mathrm{mH}]^{\mathrm{m}-}$, and myoglobin $[\mathrm{M}+\mathrm{nH}]^{\mathrm{n}+}$ reacting with myoglobin $[\mathrm{M}-\mathrm{mH}]^{\mathrm{m}-}$. (The production of myoglobin and pepsin $\left(M_{r} 34,600\right)$ anions by negative ion ESI has been described in a previous publication [35],) It was clear that the high charge states of both the anions and cations were attenuated by dual ESI source operation, but no other type of reaction was evident.

\section{Operation with ESI and Discharge Sources of the Same Polarity}

We have also investigated the combination of positive discharge/positive ESI using melittin as the analyte. The positive discharge source employed a hollow needle through which flowing gas could pass. These reactions were explored in both glass and metal inlet/reactors and with and without air or $\mathrm{N}_{2}$ flowing through 
the needle. In contrast to the opposite-polarity reaction studies described earlier (see Operation with ESI and Discharge Sources of Opposite Polarities), ESI mass spectrometry studies employing these same-polarity (positively charged) dual ionization sources at low temperatures (e.g., $140^{\circ} \mathrm{C}$ in the $1 \mathrm{~mm}$ i.d. metal capillary, $O S=+390 \mathrm{~V}$, no air or $\mathrm{N}_{2}$ flow) showed $d e-$ creased solvation accompanying discharge operation ( 30 $\mu \mathrm{A})$. Under these conditions, the polypeptide [M+ $\mathrm{nH}]^{\mathrm{n}+}$ abundances were observed to increase by 150-200\% with discharge operation, presumably because of the reduction in solvation. At $170^{\circ} \mathrm{C}$, the $[\mathrm{M}+\mathrm{nH}]^{\mathrm{n}+}$ abundances increased by only $25 \%$ with discharge operation, while at still higher temperatures, where solvent adduct contributions were minimized (e.g., $270^{\circ} \mathrm{C}$ ), the $[\mathrm{M}+\mathrm{nH}]^{\mathrm{n}+}$ abundances decreased by $10 \%$ under discharge operation. As a comparison of the amount of solvation under various conditions, we evaluated the abundance ratio of desolvated molecular ions, that is,

$$
\begin{aligned}
& \left([\mathrm{M}+4 \mathrm{H}]^{4+}+[\mathrm{M}+5 \mathrm{H}]^{5+}\right) / \\
& \left(\sum_{n=0}^{4}\left[\mathrm{M}+4 \mathrm{H}+\mathrm{nCH}_{3} \mathrm{OH}\right]^{4+}\right. \\
& \left.+\left[\mathrm{M}+5 \mathrm{H}+\mathrm{nCH}_{3} \mathrm{OH}\right]^{5+}\right)
\end{aligned}
$$

This ratio reflects the contribution of desolvated melittin ions relative to the total melittin ion signal in the mass spectrum. Only the $4+$ and $5+$ charge states were used in the ratio because of their dominance under these conditions. Only solvent adduction of $\mathbf{n} \leq$ 4 was used because larger solvent clusters (especially at $140^{\circ} \mathrm{C}$ ) were unresolved, possibly due to contributions from mixed $\mathrm{H}_{2} \mathrm{O} / \mathrm{CH}_{3} \mathrm{OH}$ clusters. Thus, we suspect that this ratio somewhat overestimates the contribution of unsolvated: solvated melittin at low temperatures where solvation greater than $n=4$ becomes significant. Methanol was the dominant adduct for melittin ions solvated by 1 to 4 solvent molecules at 140 and $170^{\circ} \mathrm{C}$. At $140^{\circ} \mathrm{C}$ the ion abundance ratios for discharge "on" and "off" werc 0.58 and 0.43 , respectively, and 0.78 and 0.71 at $170^{\circ} \mathrm{C}$, indicating enhanced desolvation with the discharge "on." Melittin ions solvated by methanol were not observed with the $270^{\circ} \mathrm{C}$ capillary with the discharge "on" or "off," although very small contributions from $\mathrm{H}_{2} \mathrm{O}$ adducts were observed.

The reasons for the reduction in solvation under discharge operation are not well understood. Possibly, clustering of solvent about the positively charged discharge ions in the interaction region of the inlet/ reactor reduced the amount of free solvent molecules available for clustering downstream in the supersonic expansion. Because the positively charged discharge ions are expected to repel the $[\mathrm{M}+\mathbf{n H}]^{\mathrm{n}+}$ ions, there is no likely direct mechanism to transfer solvent from solvated discharge cations to the polypeptide analyte ions, unlike the case of +ESI/ - discharge operation, where increased solvation accompanied discharge operation. Nevertheless, because the solvent vapor and ion densities are estimated to differ by approximately six orders of magnitude, it is hard to believe that the solvation of discharge cations in the inlet could have been large enough to reduce the solvent vapor concentration noticeably. Further study is needed to understand these observations.

In additional studies, employing the glass capillary inlet with metal apertures (see Experimental) under conditions which would be considered "very warm" for that inlet/reactor $\left(180^{\circ} \mathrm{C}, \mathrm{OS}=+230 \mathrm{~V}\right)$, a small amount of melittin molecular ion dissociation was observed to accompany positive discharge operation, yielding product ions similar to those noted previously in the collisional dissociation of melittin [21]. Initially, we suspected that these product ions might arise from chemical ionization (CI) of neutral products resulting from thermally induced dissociation (TID) $[24,25]$ in the capillary. Further discharge studies under hightemperature conditions yielding significant TID have not provided any direct evidence for CI of neutrals, however. We currently attribute the enhanced dissociation to the effect on CAD in the OS region to reduced solvation. Evaporation of solvent molecules dissipates some of the energy acquired from collisions in the OS region, making more highly solvated molecules less likely to undergo CAD. Indeed, reduced dissociation is observed for $[\mathbf{M}+\mathbf{n H}]^{\mathfrak{n}+}$ ions under negative discharge operation. Because the solvation differences observed in positive discharge "on" and "off" mass spectra are less pronounced at high capillary temperatures, we also expect differences in the amount of dissuciation to be less pronounced under these conditions. More work is needed to fully understand these systems, and efforts toward this goal are underway.

\section{Conclusions}

A simple flow reactor has been described which allows the study of broad classes of ion-ion reactions. The multiple inlet design could also have utility in the simultaneous introduction of multiple reactants or samples and provides a simple way to introduce a calibrant or marker without adulterating the sample solution. Alternatively, neutral reaction gases may be introduced into one or more arms of such an inlet [18]. Here its use is demonstrated in reactions between discharge- and ESI-generated ions, and between ESIgenerated cations and anions. The cation-anion reactions generally displayed a shift to lower charge (higher mass-to-charge ratio) in the products' charge state distributions and the transfer of solvent molecules to the macromolecule products. The cation-cation reaction yielded less highly solvated analyte ions, although the reasons for this behavior are not yet understood. 
These studies, along with those described in an earlier report [17], provide the first examples of gasphase ion-ion reactions with high molecular weight species. Although more work is needed to ascertain whether complete neutralization, production of low charge states exceeding the mass-to-charge ratio range of our instrument, or other processes play a significant role in these reactions, such lechniques hold promise for future studies of proton and electron transfer, dissociation, and derivatization of large gas-phase ions.

\section{Acknowledgments}

We acknowledge the support of the U.S. Department of Energy through the Office of Health and Environmental Research and through internal Exploratory Research of the Molecular Science Research Center (Contract DE-AC06-76RLO 1830). Pacific Northwest Laboratory is operated by Battelle Memorial Institute.

\section{References}

1. Armstrong, D. A. Radiat. Phys. Chem. 1982, 20, 75-86.

2. Bates, D. R. Ado. At. Mol. Phys. 1985, 20, 1-40.

3. (a) Aberth, W. H.; Peterson, J. R. Phys. Rev. 1970, 1, 158-165; (b) Peterson, J, R.; Aberth, W. H; Moseley, J. T.; Sheridan, J. R. Phys. Rev. A 1971, 3, 1651-1657.

4. (a) Dole, M.; Mack, L. L.; Hines, R. L.; Mobley, R. C.; Ferguson, L. D.; Alice, M. B. I. Chem. Phys. 1968, 49, 2240-2249; (b) Mack, L. L.; Kralik, P.; Rheude, A.; Dole, M. I. Chem. Phys. 1970, 52, 4977-4986; (c) Dole, M.; Cox, H. L. Jr.; Gieniec, J. J. Adv. Chem. Ser. 1973, 125, 73-84; (d) Teer, D.; Dole, M. I. Polym. Sci. 1975, 13, 985-995.

5. (a) Fenn, J. B.; Mann, M.; Meng, C. K.; Wong, S. F, Whitehouse, C. M. Science 1989, 246, 64-71; (b) Fenn, J. B.; Mann M.; Meng, C. K.; Wong, S. F.; Whitehouse, C. M. Mass Spectrom Rev. 1990, 9, 37-70; (c) Mann, M. Org. Mass Spectrom. 1990, 25, 575-587.

6. Huang, E. C.; Wachs, T,; Conboy, J. J.; Herion, J. D. Anal. Chem. 1990, 62, 713A-725A.

7. Bruins, A. P. Mass Spectrom. Rev. 1991, 10, 53-77.

8. (a) Smith, R. D.; Loo, J. A.; Barinaga, C. J.; Edmonds, C. G.; Udseth, H. R. I. Am. Soc. Mass Spectrom. 1990, 1, 53-65; (b) Smith, R. D.; Loo, J. A.; Edmonds, C. G.; Barinaga, C. J.; Udseth, H. R. Anal. Chem. 1990, 62, 882-899; (c) Smith, R. D; Loo, J. A.; Ggorzalek Loo, R. K.; Busman, M.; Udseth, H. R. Mass Spectrom. Rev. 1991, 10, 359-451.

9. Chowdhury, S. K.; Katta, V.; Chait, B. T. Rapid Commun. Mass Spectrom. 1990, 4, 81-87.

10. Chowdhury, S. K; Katta, V.; Beavis, R. C.; Chait, B. T. J. Am. Soc. Mass. Spectrom. 1990, 1, 382-388.

11. Katta, V, Chowdhury, S. K.; Chait, B. T. J. Am. Chem. Soc. 1990, 112, 5348-5349.

12. (a) Jayaweera, P.; Blades, A. T.; Ikonomou, M. G.; Kebarle, P. J. Am. Chem. Soc. 1990, 112, 2452-2454; (b) Blades, A. T. Jayaweera, P.; Ikonomou, M. G.; Kebarle, P. I. Chent. Phys 1990, 92, 5900-5906; (c) Blades, A. T.; Jayaweera, $P$. Ikonomou, M. G.; Kebarle, P. Int. I. Mass Spectrom. Ion Proc. 1990, 101, 325-336; (d) Ikonomou, M. G; Blades, A. T. Kebarle, P. Anal. Chem. 1990, 62, 957-967.

13. (a) Siu, K. W. M; Gardner, G. J.; Berman, S. S. Rapid Commun. Mass Spectrom. 1988, 2, 69-71; (b) Siu, K.W. M. Gardner, G. J.; Berman, S. S. Rapid Commun. Mass Spectrom.
1988, 2, 201-204; (c) Siu, K. W. M.; Gardner, G. J.; Berman, S. S. Org. Mass Spectrom. 1989, 24, 931-942; (d) Quillam, M. A; Thomson, B. A.; Scott, G. J.; Siu, K. W. M. Rapid Commun. Mass Spectrom. 1989, 3, 145-150.

14. Van Berkel, G. J.; McLuckey, S. A.; Glish, G. L. Aral. Chem. 1991, 63, 1098-1109.

15. Bitsch, F, Dietrich-Buchecker, C. O.; Khemiss, A.-K.; Sauvage, J.-P.; Van Dorsselaer, A. I. Am. Chem. Soc. 1991, 113, 40234025 .

16. Stults, J. T.; Marsters, J. C. Rapid Commun. Mass Spectrom. 1991, 5, 359-363.

17. Ogorzalek Loo, R. R,; Udseth, H. R,; Smith, R. D. J. Phys, Chem. 1991, 95, 6412-6415.

18. (a) Ogorzalek Loo, R. R.; Loo, J. A.; Udseth, H. R.; Fulton, J. L. Smith, R. D. Rapid Commun. Mass Spectrom. 1992, 6, 159-165; (b) Winger, B. E.; Light-Wahl, K. J;; Smith, R. D. J. Am. Soc. Mass Spectrom., in press.

19. Smith, R. D.; Olivares, I. A.; Nguyen, N. T.; Udseth, H. R. Anal. Chem. 1988, 60, 436-441.

20. (a) Smith, R. D.; Barinaga, C. J.; Udseth, H. R. Anal. Chem. 1988, 60, 1948-1952; (b) Loo, J. A.; Udseth, H. R.; Smith, R. D. Biomed. Environ. Mass Spectrom. 1988, 17, 411-414.

21. Barinaga, C J.; Edmonds, C. G.; Udseth, H. R.; Smith, R. D. Rapid Commun. Mass Spectrom. 1989, 3, 160-164.

22. Loo, J. A.; Udseth, H. R.; Smith, R. D. Rapid Commun. Mass Spectrom. 1988, 2, 207-210.

23. Whitehouse, C. M.; Dreyer, R. N.; Yamashita, M; Fenn, J. B. Artal. Chem. 1985, 57, 675-679.

24. (a) Rockwood, A. L.; Busman, M.; Udseth, H. R.; Smith, R. D. Rapid Commun. Mass Spectrom. 1991, 5, 582-585; (b) Rockwood, A. L.; Busman, M.; Smith, R. D. Int. J. Mass Spectrom. Ion Proc. 1991, 111, 103-129.

25. Busman, M.; Rockwood, A. L.; Smith, R. D. J. Phys. Chem 1992, 96, 2397-2400.

26. (a) Dzidic, I; Carroll, D. I.; Stillwell, R. N.; Horning, M. G.; Horning, E. C. Add. Mass Spectrom. 1978, 7, 359-366; (b) Lane, D. A.; Thomson, B. A.; Lovett, A. M.; Reid, N. M. Adv. Mass Spectrom. 1980, 8, 1480-1489; (c) Harrison, A. G. Chem. Ion. Mass Spectrom. 1984, 52, 80.

27. (a) Searcy, J. Q; Fenn, J. B. J. Chem. Phys. 1974, 61, 5282-5288; (b) Zook, D. R.; Grimsrud, E. P. J. Phys. Chem. 1988, 92, 6374-6379.

28. Katta, V.; Chowdhury, S. K.; Chait, B. T. Anal. Chem. 1991, $63,174-178$.

29. McLuckey, S. A.; Glish, G. L.; Van Berkel, G. J. Anal. Chem 1991, 63, 1971-1978.

30. (a) Ikonomou, M. G.; Blades, A. T.; Kebarle, P. 1. Am. Soc. Mass Spectrom. 1991, 2, 497-505; (b) Good, A.; Durden, D. A.; Kebarle, P. I. Chem. Phys. 1970, 52, 222-229; (c) Sunner, J.; Nicul, G.; Kebarle, P. Anul. Chem. 1988, 60, 1300-1307; (d) Shahin, A. I. Chem. Phys. 1966, 45, 2600-2605; (e) Lau, Y. K.; Ikuta, S.; Kebarle, P. I. Am. Chem. Soc. 1982, 104, 1462-1469.

31. McLuckey, S. A.; Van Berkel, G. J.; Glish, G. L. I. Am. Soc. Mass Spectrom. 1992, 3, 60-70.

32. McLuckey, S. A.; Glish, G. L.; Van Berkel, G. J. Proceedings of the 39th Annual ASMS Conference on Mass Spectrometry and Allied Topics; Nashville, TN, 1991; 901-902.

33. McLuckey, S. A.; Van Berkel, G. J.; Glish, G. L. Proceedings of the 38th Annual ASMS Conference on Mass Spectrometry and Allied Topics; Tucson, AZ. 1991; 1134-1135.

34. McLuckey, S. A.; Van Berkel, G. J.; Glish, G. L. J. Am. Chem. Soc. 1990, 112, 5668-5670.

35. Loo, J. A.; Ogorzalek Loo, R. R.; Light, K. J.; Edmonds, C. G.; Smith, R. D. Anal. Chem. 1992, 64, 81-88. 